\title{
DETERMINAÇÃO DE METAIS POTENCIALMENTE TÓXICOS EM PEIXES DO RIO PARANÁ, DIVISA DE ESTADO SP - MS
}

\author{
DETERMINATION OF POTENTIALLY TOXIC METALS IN FISH FROM PARANÁ \\ RIVER, STATE DIVIDE SP - MS
}

\author{
Gabriel Murilo Gois Pavani ${ }^{1}$; Mariele Pereira de Camargo ${ }^{1}$; Daniel Ângelo \\ Macena ${ }^{1}$; Vinícius Marques Gomes ${ }^{1}$. \\ ${ }^{1}$ Universidade do Oeste Paulista - UNOESTE, Curso de Química Bacharelado, \\ Presidente Prudente, SP. \\ e-mail: viniciusmarques@unoeste.br
}

RESUMO - A pesquisa tem como finalidade avaliar as concentrações dos metais chumbo e crômio, em duas espécies de peixes, a Piranha-branca (Pristobrycon striolatus) e o Piau-três-pintas (Leporinus freiderici), por serem os mais comercializados na região de estudo. Esses elementos são conhecidos como bioacumuladores e biomagnificadores, justamente por se acumularem nos tecidos gordurosos dos seres vivos, aumentando sua concentração ao longo do ciclo de vida da espécie. Os peixes foram adquiridos de pescadores da região de Panorama-SP, coletados no rio Paraná, divisa SP-MS. O preparo e a digestão das amostras foram baseados no método descrito por Santos e Silva (2015). Os elementos foram quantificados por espectrometria de absorção atômica em chama (FAAS). De acordo com os resultados obtidos, os teores dos metais analisados estavam acima dos limites máximos permitidos pela legislação brasileira, portanto impróprio para o consumo humano.

Palavras-chave: peixes; metais potencialmente tóxicos; chumbo; crômio.

ABSTRACT - The aim of this research was to evaluate the concentrations of lead and chromium in two species of fish, the Piranha-branca (Pristobrycon striolatus) and Piau-tres-pintas (Leporinus freiderici), as they are the most commercialized in the study region. These elements are known as bioaccumulators and biomagnifiers, precisely because they accumulate in the fatty tissues of living beings, increasing their concentration throughout the life cycle of the species. The fish were purchased from fishermen from the region of Panorama-SP, collected on the Paraná River, SP-MS. The preparation and the digestion of the samples were based on the method described by Santos and Silva (2015). The elements were quantified by flame atomic absorption spectrometry (FAAS). According to the results obtained, the contents of the analyzed metals were above the maximum limits allowed by Brazilian legislation, therefore unfit for human consumption.

Keywords: fish; potentially toxic metals; lead; chromium. 


\section{INTRODUÇÃO}

Atualmente, muito se discute acerca de aderir ao consumo de peixes em nossa alimentação, por se tratar de um alimento rico em nutrientes, proteínas e vitaminas, dentre os quais necessitamos para manter nossa saúde em dia. No entanto, alguns problemas podem acompanhar tal ingestão, já que tais pescados podem apresentar metais nocivos à saúde humana por estar acima do limite ideal para consumo, ocasionando intoxicações e levando até mesmo a morte (MASSABNI, 2006).

Esses metais tóxicos são oriundos de atividades industriais, onde é necessário o uso dos mesmos nas etapas de produção, obtendo-se ao final de cada processo, resíduos ricos em substâncias químicas prejudiciais, em doses elevadas, a vida aquática e humana. Entre as principais fontes desses químicos se destacam as atividades de mineração, queima de combustíveis fósseis e até mesmo efluentes domésticos que acabam atingindo os cursos d'água sem qualquer tratamento (CAMPOS et al., 2009).

A maioria dos seres vivos precisa de uma pequena fração específica de certos metais, como cálcio, ferro, zinco e outros chamados de metais essenciais. Já os metais como o chumbo, cádmio, crômio e mercúrio são chamados de metais não essenciais, ou seja, não possuem nenhuma função vital para o nosso organismo, por serem extremamente tóxicos (MASSABNI, 2006). Sendo assim, esses elementos presentes no tecido dos peixes, estão relacionados ao poder de bioacumulação e biomagnificação que possuem, ocorrendo ao longo de todos os níveis tróficos (REDAÇÃO, 2013).

Os peixes comercializados são em sua maioria, provenientes de águas de rios e oceanos que não estão apropriados para a vida aquática por conta dos problemas já citados do início. Essa situação se agrava pelo fato de que as substâncias se acumulam nos organismos dos vertebrados, conforme a idade e também ao nível trófico em que eles se encontram. Quanto mais elevado for o nível, maior será a concentração desses elementos (MACKENZIE \& SUSAN, 2016).

O principal problema são as atividades antrópicas, descartando diversas substâncias tóxicas no ambiente aquático, ambiente que pode ser de um simples lago, rios até mares e oceanos. O rio escolhido para o presente estudo foi o Rio Paraná, na região de Panorama - SP, que é considerado o maior da América do Sul depois do Amazonas (ITAIPU, 2017).

A bacia hidrográfica brasileira é enorme, com uma rica variedade de peixes. O rio Paraná, tem aproximadamente 500 tipos espécies, com diversas características distintas, onde os mesmos são importantes bioindicadores usados em estudos de ambiente aquático em determinados locais (CASATTI; LANGEANI; CASTRO, 2001).

As espécies escolhidas para serem analisadas são a Piranha-branca (Pristobrycon striolatus) espécie carnívora, e o Piau três pintas (Leporinus freiderici), espécie onívora, por serem comuns na região.

O local de estudo, tem a pesca como um grande atrativo turístico, pois apresenta boa estrutura de atividades de lazer às margens do rio Paraná, atraindo turistas, além de tê-la como uma das formas de fontes de renda.

Este estudo foi realizado com o objetivo de avaliar duas espécies de peixes do Rio Paraná para determinar se estão próprios para o consumo humano e dentro dos valores máximos permitidos conforme recomendado pela legislação, quantificando os teores de chumbo e crômio nas duas espécies estudadas utilizando a espectrometria de absorção atômica em chama como ferramenta para análise qualitativa e quantitativa dos metais potencialmente tóxicos.

\section{MÉTODO}

As análises foram realizadas nos laboratórios de Química, localizados no Bloco Q, da Universidade do Oeste Paulista - UNOESTE de Presidente Prudente, Estado de São Paulo.

Os pescados escolhidos, Piau-três-pintas e a Piranha-branca, foram adquiridos de pescadores na região de Panorama, em três meses distintos, abril, maio e junho respectivamente, levando em consideração o tamanho e idade dos mesmos, dando preferência aos exemplares maiores e mais velhos.

Os exemplares adquiridos no mês de abril tinham $30 \mathrm{~cm}$ de comprimento para o piau e 24 $\mathrm{cm}$ para a piranha. No mês de maio, $35 \mathrm{~cm}$ o piau e $34 \mathrm{~cm}$ a piranha, e em junho $25 \mathrm{~cm}$ o piau e 27 $\mathrm{cm}$ a piranha.

Depois que adquiridos, os peixes foram devidamente embalados em sacos plásticos, e transportados sobre refrigeração em caixas térmicas até o local de destino, sendo mantidos 
congelados a uma temperatura de $-18 \mathrm{C}^{\circ}$ até serem enviados ao laboratório da universidade.

Primeiramente, retirou-se a pele $e$ escamas, para em seguida retirar as porções do tecido muscular. Depois seguiram para estufa, e secaram por cerca de 2 dias.

Após secagem, as amostras foram maceradas e homogeneizadas. Em seguida pesou-se aproximadamente $2,0 \mathrm{~g}$ de cada amostra, e às transferiu para seus devidos tubos de digestão, acondicionado em bloco digestor.

Foi adicionado $10,0 \mathrm{~mL}$ de solução de ácido nítrico concentrado, em cada tubo com as devidas amostras e submeteu-se ao aquecimento de $120{ }^{\circ} \mathrm{C}$, e $1 \mathrm{~mL}$ de solução de peróxido de hidrogênio $30 \%(\mathrm{v} / \mathrm{v})$ a cada 30 minutos, deixando a amostra sob aquecimento até o final da digestão.

Ao final os extratos foram filtrados usando papel filtro e avolumados em um balão volumétrico de 25,0 mL com água Mili-Q (18 $\mu \Omega)$. Em seguida, foram transferidos para seus respectivos frascos e guardados, até serem enviadas para o laboratório da universidade responsável pela leitura dos metais usando FAAS. O preparo e digestão das amostras dos peixes foram baseados no método descrito por Santos e Silva (2015). Este procedimento foi realizado em quadruplicada para cada espécie de peixe.

\section{RESULTADOS}

Os ensaios foram realizados para as amostras das duas espécies de peixes estudados, com um total de 8 , sendo 4 de cada espécie.

Para a espécies Piranha-branca (Pristobrycon striolatus), foram obtidos os resultados apresentados nas de tabelas 1,2 e 3, de acordo com o mês de coleta.

TABELA 1. Teores de chumbo e crômio obtidos para amostras de Piranha-branca em abril.

\begin{tabular}{c|c|c}
\hline Amostra & $\begin{array}{c}{[\mathbf{P b}]} \\
\mathbf{m g} / \mathbf{k g}\end{array}$ & $\begin{array}{c}{[\mathbf{C r}]} \\
\mathbf{m g} / \mathbf{k g}\end{array}$ \\
\hline $\mathbf{1}$ & 15,34 & 32,27 \\
\hline $\mathbf{2}$ & 5,615 & 188,9 \\
\hline $\mathbf{3}$ & 12,03 & 123,6 \\
\hline $\mathbf{4}$ & 5,793 & 88,75 \\
\hline Médias & 9,696 & 108,4 \\
\hline
\end{tabular}

Fonte: próprio autor.
TABELA 2. Teores de chumbo e crômio obtidos para amostras de Piranha-branca em maio.

\begin{tabular}{c|c|c}
\hline Amostra & $\begin{array}{c}\text { [Pb] } \\
\mathbf{m g} / \mathbf{k g}\end{array}$ & $\begin{array}{c}{[\mathbf{C r}]} \\
\mathbf{m g} / \mathbf{k g}\end{array}$ \\
\hline $\mathbf{1}$ & 16,96 & 107,8 \\
\hline $\mathbf{2}$ & 40,37 & 93,67 \\
\hline $\mathbf{3}$ & 25,91 & 94,80 \\
\hline $\mathbf{4}$ & 40,02 & 85,66 \\
\hline Médias & 30,82 & 95,50 \\
\hline
\end{tabular}

Fonte: próprio autor.

TABELA 3. Teores de chumbo e crômio obtidos para amostras de Piranha-branca em junho.

\begin{tabular}{c|c|c}
\hline Amostra & $\begin{array}{c}{[\mathbf{P b}]} \\
\mathbf{m g} / \mathbf{k g}\end{array}$ & $\begin{array}{c}{[\mathbf{C r}]} \\
\mathbf{m g} / \mathbf{k g}\end{array}$ \\
\hline $\mathbf{1}$ & 13,15 & 114,1 \\
\hline $\mathbf{2}$ & 10,22 & 157,4 \\
\hline $\mathbf{3}$ & 13,23 & 148,2 \\
\hline $\mathbf{4}$ & 32,23 & 236,2 \\
\hline Médias & 17,21 & 164,0 \\
\hline
\end{tabular}

Fonte: próprio autor.

Para a espécies Piau-Três-Pintas (Leporinus freiderici), foram obtidos os seguintes resultados apresentados nas de tabelas 4,5 e 6 respectivamente, conforme o mês de coleta.

TABELA 4. Teores de chumbo e crômio obtidos para amostras de Piau-Três-Pintas em abril.

\begin{tabular}{c|c|c}
\hline Amostra & $\begin{array}{c}{[\mathbf{P b}]} \\
\mathbf{m g} / \mathbf{k g}\end{array}$ & $\begin{array}{c}{[\mathbf{C r}]} \\
\mathbf{m g} / \mathbf{k g}\end{array}$ \\
\hline $\mathbf{1}$ & 8,218 & 132,6 \\
\hline $\mathbf{2}$ & 4,465 & 147,2 \\
\hline $\mathbf{3}$ & 21,02 & 243,1 \\
\hline $\mathbf{4}$ & 29,60 & 197,4 \\
\hline Médias & 15,82 & 180,1 \\
\hline
\end{tabular}

Fonte: próprio autor.

TABELA 5. Teores de chumbo e crômio obtidos para amostras de Piau-Três-Pintas em maio.

\begin{tabular}{c|c|c}
\hline Amostra & $\begin{array}{c}\text { [Pb] } \\
\mathbf{m g} / \mathbf{k g}\end{array}$ & $\begin{array}{c}{[\mathbf{C r}]} \\
\mathbf{m g} / \mathbf{k g}\end{array}$ \\
\hline $\mathbf{1}$ & 47,94 & 245,7 \\
\hline $\mathbf{2}$ & 31,46 & 69,86 \\
\hline $\mathbf{3}$ & 21,08 & 111,6 \\
\hline $\mathbf{4}$ & 21,71 & 131,3 \\
\hline Médias & 30,55 & 139,6 \\
\hline
\end{tabular}

Fonte: próprio autor. 
TABELA 6. Teores de chumbo e crômio obtidos para amostras de Piau-Três-Pintas em junho.

\begin{tabular}{c|c|c}
\hline Amostra & $\begin{array}{c}\text { [Pb] } \\
\mathbf{m g} / \mathbf{k g}\end{array}$ & $\begin{array}{c}{[\mathbf{C r}]} \\
\mathbf{m g} / \mathbf{k g}\end{array}$ \\
\hline $\mathbf{1}$ & 25,82 & 149,0 \\
\hline $\mathbf{2}$ & 10,47 & 86,20 \\
\hline $\mathbf{3}$ & 6,897 & 106,5 \\
\hline $\mathbf{4}$ & 23,948 & 158,0 \\
\hline Médias & 16,78 & 124,9 \\
\hline
\end{tabular}

Fonte: próprio autor.

\section{DISCUSSÃO}

De acordo com os resultados obtidos das concentrações de $\mathrm{Pb}$ e $\mathrm{Cr}$, ambas as espécies se mostraram acima dos valores limites estabelecidos pela legislação vigente, que são de $0,30 \mathrm{mg} / \mathrm{kg}$ para $\mathrm{Pb}$ e $0,1 \mathrm{mg} / \mathrm{kg}$ para $\mathrm{Cr}$.

Os valores médios das concentrações dos metais analisados para a Piranha durante os 3 meses, ficou em torno de $19,24 \mathrm{mg} / \mathrm{kg}$ para chumbo, e 122,6 mg/kg para crômio, excedendo bastante os limites permitidos para a espécie.

Já no Piau, a média das concentrações encontradas durante os respectivos meses de análises, também se revelaram bem acima, com valores de $21,05 \mathrm{mg} / \mathrm{kg}$ para chumbo e de 148,2 $\mathrm{mg} / \mathrm{kg}$ para crômio.

Nota-se que o crômio apresentou maior concentração em comparação com o chumbo nas duas espécies de peixe, podendo ser provenientes dos setores industriais próximos à região, como serralherias e curtumes.

O chumbo foi encontrado em maiores concentrações no mês de maio para ambas as espécies, já o crômio não coincidiu de ser no mesmo mês, pois a piranha apresentou-se em maiores quantidades no mês de junho, e o piau no mês de abril.

O fato de a média das concentrações serem superiores no mês de junho, possivelmente é explicado por ter sido uma época mais chuvosa, que contribui para o aumento dos teores de metais nos rios por lixiviação.

Esperava-se que fossem encontrados maiores concentrações dos metais na piranha por ser um peixe predatório (biomagnificação), porém os resultados não indicaram diferenças significativas entre as espécies, o que pode ser apontado pelas possíveis diferenças de idade e peso entre os peixes, visto que um peixe mais velho possui um maior tempo de exposição, e também devido a alimentação de cada um, aliado ao ambiente em que percorreram em suas trajetórias em épocas de cheias ou reprodução.

\section{CONSIDERAÇÕES FINAIS}

Os peixes adquiridos na região de Panorama-SP para o estudo estão impróprios para o consumo humano, pois excederam os limites máximos permitidos pela legislação brasileira, indicando que o rio Paraná está com altos teores de metais potencialmente tóxicos, representando sérios riscos à saúde das pessoas que consome tais pescados, aliado ao impacto que causa ao ambiente aquático no geral, interferindo diretamente na saúde dos animais, comprometendo a função de seus órgãos e até mesmo a reprodução.

Diante disso, torna-se fundamental que haja outros estudos abrangendo regiões próximas a divisa SP-MS do rio Paraná, para que forneça maiores evidências de contaminações, e seja feito um controle de efluentes domésticos e industriais mais eficazes, para se evitar o aumento das concentrações desses elementos tóxicos.

\section{REFERÊNCIAS}

BRASIL. Decreto no 55871, de 26 de março de 1965. Modifica o Decreto no 50.040, de 24 de janeiro de 1961, referente a normas reguladoras do emprego de aditivos para alimentos, alterado pelo Decreto no 691, de 13 de março de 1962.

Diário Oficial da União. Brasília, DF, 13 marc. 1962.

BRASIL. Ministério da Saúde. ANVISA- Agência Nacional de Vigilância Sanitária. Resolução RDC $N^{\circ} 42$, de 29 de agostos de 2013. Dispõe sobre o Regulamento Técnico MERCOSUL sobre Limites Máximos de Contaminantes Inorgânicos em Alimentos. Diário Oficial da União. Brasília, DF, 29 ago. 2013.

BRASIL. Ministério do Meio Ambiente. Instrução Normativa MMA N ${ }^{\circ} 30$, De 13 De Setembro De 2005. Dispõe sobre regulamentar o uso de determinados petrechos na bacia Hidrográfica do Rio Paraná. 2005-ICMBio. Brasília, DF, 30 set. 2005.

CAMPOS, A. E. L. et al. Avaliação da contaminação do Igarapé do Sabino (Bacia do rio tiribi) por metais pesados, originados dos 
resíduos e efluentes do aterro da ribeira, em São Luis, Maranhão. Quím. Nova. São Paulo, v. 32, n. 4, fev., 2009.

CASATTI, L; LANGEANI, F; CASTRO, R. M. C. Peixes de riacho do parque estadual Morro do Diabo, Bacia do Alto Rio Paraná, SP. Biota Neotrop.

Campinas, v. 1, n. 1-2, p. 1-15, jan. 2001.

https://doi.org/10.1590/S1676-

06032001000100005

ITAIPU BINACIONAL. Rio Paraná. Disponível em:<https://www.itaipu.gov.br/energia/rioparana>. Acesso em: 29 jun. 2017.

MACKENZIE L. D; SUSAN J. M. Princípios de Engenharia Ambiental. 3. Ed. Porto Alegre: AMGH, 2016.

MASSABNI, A. C. Os metais e a Saúde Humana. Química Online - Conselho Regional de Química $4^{\circ}$ Região. 2006.

REDAÇÃO. Como a bioacumulação pode prejudicar a cadeia alimentar do homem. Disponível em:

<http://www.pensamentoverde.com.br/meioambiente/bioacumulacao-prejudicar-cadeiaalimentar-homem/>. Acesso em: 19 out. 2017.

REPULA, M. M. C. et al. Biomonitoramento de $\mathrm{Cr}$ e $\mathrm{Pb}$ em peixes de água doce. Quím. Nova, Guarapuava, v. 35, n. 5, 905-909, fev. 2012.

ROCHA, A.F. Cádmio, Chumbo, Mercúrio - A problemática destes metais pesados na Saúde Pública?. 2009. 48 f. Monografia (Especialização)

- Faculdade de Ciências da Nutrição e

Alimentação Universidade do Porto, 2009.

SANCHES, P. V. et al. Caracterização do desenvolvimento inicial de leporinus friderici (osteichthyes, anostomidae) da bacia do rio paraná, brasil. Acta scientiarum. Maringá, v. 23, n. 2, p. 383-389, jan. 2001.

SANTOS, S. O; SILVA, C. A. Determinação dos metais ferro e zinco em peixes marinhos comercializados em Aracaju, SE, Salvador, BA e Maceió, AL. In: SEMINÁRIO DE INICIAÇÃO CIENTÍFICA E PÓS-GRADUAÇÃO DA EMBRAPA TABULEIROS COSTEIROS, 5., 2015, Aracaju. Anais... Brasília, DF: Embrapa, 2015. p. 103-110. 